\title{
Turbulence and stratification in Priest Pot, a productive pond in a sheltered environment
}

\author{
Andrew M Folkard*, Amy J Sherborne \\ Department of Geography, Lancaster Environment Centre, University of Lancaster, Lancaster \\ LA1 4YB, United Kingdom
}

Michael J Coates

School of Life and Environmental Sciences, Deakin University, PO Box 423, Warrnambool

Victoria 3280, Australia

Total text pages: 24 (including References and Figure captions)

Total number of tables: 0

Total number of figures: 5

* Corresponding author: Phone: +44 1524 593755; Fax: +44 1524 874099; Email: a.folkard@lancaster.ac.uk 


\begin{abstract}
Priest Pot is an example of the abundant ponds which, collectively, contribute crucially to species diversity. Despite extensive biological study, little has been reported about the physical framework which supports its ecological richness. This paper elucidates the physical character of Priest Pot's water column and thus that of similar waterbodies. Vertical thermal microstructure profiles were recorded during summer 2003, and analysed alongside concurrent meteorological data. During summer stratification, the thermal structure appeared to be dominated by surface heat fluxes. Surface wind stress, limited by sheltering vegetation, caused turbulent overturns once a surface mixed layer was present, but appeared to contribute little to setting up the thermal structure. Variations in full-depth mean stratification occurred pre-dominantly over seasonal and $\sim 5$-day time scales, the passage of atmospheric pressure systems being posited as the cause of the latter. In the uppermost $\sim 0.5 \mathrm{~m}$, where the stratification varied at sub-daily time scales, turbulence was active (sensu Ivey and Imberger, 1991) when this layer was mixed, with dissipation values $\varepsilon \sim 10^{-8} \mathrm{~m}^{2} \mathrm{~s}^{-3}$ and vertical diffusivity $\mathrm{K}_{\mathrm{Z}}=10^{-4}-10^{-6} \mathrm{~m}^{2} \mathrm{~s}^{-1}$. Where the water column was stratified, turbulence was strongly damped by both buoyancy and viscosity and $\mathrm{K}_{\mathrm{Z}}$ was an order of magnitude smaller. Vertical transport in the mixed layer occurred via many small overturns (Thorpe scale rms and maximum values typically $0.02 \mathrm{~m}$ and $0.10 \mathrm{~m}$ respectively) and seston were fully mixed through the water column.
\end{abstract}

Keywords: Stratification, turbulence, ponds, meteorological forcing, thermal microstructure 


\section{Introduction}

Priest Pot (surface area $\sim 1$ ha., maximum depth $3.5 \mathrm{~m}$ ) is a pond located in the English Lake District $\left(54^{\circ} 22^{\prime} \mathrm{N}, 3^{\circ} 00^{\prime} \mathrm{W}\right.$, at $66 \mathrm{~m}$ above sea level) which is approximately elliptical in shape and has almost concentric bathymetric contours throughout. It lies within a small area of marshland and is surrounded by a carr of mature trees and large bushes. It has no significant surface water inflows or outflows and its residence time is thus very long. Scientific research has been carried out on Priest Pot for over fifty years, mainly from a biological perspective. As a result, much information on its species richness (to date around 1000 microbial taxa have been recorded) and biochemistry has been garnered and an unusually high level of chemical and microbial compartmentalisation of the water column observed (Finlay and Maberley, 2000).

Ponds may be loosely defined as lentic waterbodies that are sufficiently small and shallow to make them qualitatively different from lakes (see also Biggs et al., 2005) and are very common in both temperate and tropical environments (Oertli et al., 2005 and Talling, 2001, respectively). For example, in Great Britain approximately 97\% - some 400,000 - of all standing waterbodies have surface areas of less than five hectares (Biggs et al., 2005). Ponds are usually highly biologically productive and support an unusually diverse variety of species in a small space (Finlay and Maberley, 2000; Williams, 2004). Furthermore, they are estimated to be disappearing at a rate of several thousand per year (Williams et al., 1998). Key questions in pond research reflect the importance of their contribution to biodiversity, and focus primarily on controls on their trophic status and species richness and the mechanisms which dominate their biogeochemical cycles. The shallowness of ponds is important in that it increases the extent to which their benthic regions are affected by atmospheric processes and air-water exchanges at the water surface (Talling, 2001). However, when ponds have very limited surface areas, and moreover are sheltered by 
surrounding vegetation, they can become very strongly stratified. This counteracts the effect of their shallowness, by limiting exchanges between the bottom water and the atmosphere (Spence et al., 2003).

As for Priest Pot, most studies of other ponds have been carried out from a biological perspective (for recent reviews see, for example, Biggs et al., 2005; Oertli et al., 2005). This is not surprising, given that their primary value lies in their contribution to species richness. However, relatively little research has been carried out into their thermal and hydrodynamic nature. This is an important omission, since these physical factors are central to the structuring of the water column that is the essential framework for their highly diverse ecosystems. For example, near surface, diurnal thermoclines may trap organisms or chemical matter in the highly irradiated near surface water (Xenopoulos and Schindler, 2001). Near surface heating and cooling also affects the growth of mosquito and fly larvae which live in this part of the water column (Jacobs et al., 1997). More generally, measurement of the time and spatial scales of turbulent mixing processes are required to determine rates of vertical cycling of phytoplankton and therefore quantify their irradiation (MacIntyre, 1993; Lorke, 1998).

Studies have been made of thermal stratification of small, standing waterbodies, although most of this work has concerned artificial structures designed for stormwater retention, aquaculture etc. Jacobs et al. (1998) studied temperature variations in a pool $6 \mathrm{~m}$ across and $0.35 \mathrm{~m}$ deep during summer. Even in such a constrained environment they found a significant depth-dependence in the amplitude of the temperature variations within the water. More detailed work using thermal microstructure probes to identify turbulent mixing processes has been carried out on a number of small and/or shallow natural lakes using techniques developed in larger lakes and oceans (e.g., MacIntyre, 1993; Lorke, 1998). These have found different mixing processes - dominated by convective cooling and wind stress- 
induced shear - acting together over short time scales to mediate vertical migration of phytoplankton through the light attenuation curve, via both relatively large-scale coherent advective motions and diffusion due to smaller scale turbulent activity.

A priori, the physics of temperate zone ponds may appear relatively straightforward: diurnal and seasonal ambient temperature variations would be expected to dominate, and give the ponds a seasonal monomictic or dimictic character, on which one would expect significant nocturnal convective cooling and daytime surface heating patterns to be superimposed. Energetic, episodic storm events would be expected to largely overturn them. There is, however, little detailed information on their thermal and hydrodynamic structure to either support or contradict this assumed character. The contribution of this paper is to provide such information for Priest Pot specifically, and to interpret its more widely-relevant implications.

To summarise, the specific objectives of the study were to:

- determine the overall thermal structure of the water column;

- determine how this varied over time scales varying from sub-daily to seasonal, and explain these patterns in terms of the environmental context of the pond;

- determine the distribution of turbulent mixing activity within the water column, identify its character and infer its ecological implications.

\section{Methods}

Thermal microstructure profiles of the water column were obtained from a mooring at the approximate centre of Priest Pot on 14 days during July-October 2003 using a SelfContained Autonomous Micro-Profiler or SCAMP (see http:/www.pme.com/scamp.htm). It was deployed in ascending mode, in which the instrument fell to an operator-defined depth at an angle, released a weight, and then rose vertically through water thus undisturbed by its descent, with a velocity of $\sim 0.1 \mathrm{~m} \mathrm{~s}^{-1}$. Temperature was recorded at $100 \mathrm{~Hz}$, giving a spatial 
resolution of $\sim 1 \mathrm{~mm}$. Several profiles, approximately ten minutes apart, were recorded on each fieldwork day in order to obtain a sufficiently large dataset of turbulent parameter values for analysis. At the profiling location during the fieldwork period, the high seston concentrations found within the water column strongly attenuated the light such that the Secchi depth was approximately $1 \mathrm{~m}$ : significantly less than the full depth of the pond.

In order to characterize the general thermal structure of the water column, the individual profiles from each day were Thorpe-ordered into monotonically increasing profiles by sorting the depth and density series individually (following Thorpe, 1977). From these monotonic profiles, the average temperature at each depth was calculated, and a mean profile for the day thus calculated. Typically, variations in temperature measurements at any given depth between all the individual profiles were of the order of $0.1^{\circ} \mathrm{C}$. The overall buoyancy frequency of this mean profile was then calculated as

$$
\overline{\mathrm{N}}=\sqrt{\frac{\mathrm{g}}{\rho_{0}} \frac{\Delta \rho}{\Delta z}}
$$

where $g$ is gravitational acceleration, $\rho_{0}$ is the mean water density, and $\Delta \rho / \Delta z$ is the gradient of the best fit straight line to the density profile. To quantify the variation in stratification, the buoyancy frequency was also calculated for various segments of the mean profile.

The individual, raw profiles were divided into segments 128 data points long (corresponding to approximately $13 \mathrm{~cm}$ of depth) in order to determine the depth variation of turbulence characteristics. The turbulent kinetic energy dissipation rate $\varepsilon$ was calculated for each segment using Batchelor curve fitting (Dillon and Caldwell, 1980). The root mean square and maximum Thorpe scales, $\mathrm{L}_{\mathrm{T}}$ and $\mathrm{L}_{\mathrm{Tmax}}$, were calculated (Thorpe, 1977) and taken to represent r.m.s. and maximum length scales of turbulent overturns in each segment respectively (root mean square values being calculated from non-zero displacements values 
only). The Ozmidov scale $\mathrm{L}_{\mathrm{O}}=\left(\varepsilon / \mathrm{N}^{3}\right)^{1 / 2}$ (where $\mathrm{N}$ is the local buoyancy frequency of the segment), was calculated and taken to represent the maximum scale to which turbulent eddies may grow before becoming significantly constrained by buoyancy.

The turbulent velocity scale was calculated as $u=\left(\varepsilon \mathrm{L}_{\mathrm{T}}\right)^{1 / 3}$ (following, for example, Ivey and Imberger 1991). This allowed calculation of the turbulent Froude and Reynolds numbers, respectively $\mathrm{Fr}_{\mathrm{T}}=\mathrm{u} / \mathrm{NL}_{\mathrm{T}}$ and $\mathrm{Re}=\mathrm{uL}_{\mathrm{T}} / v$ where $\mathrm{v}$ is the fluid viscosity. This enabled the construction of hydrodynamic phase diagrams (Ivey and Imberger, 1991), which allowed the relative importance of viscosity and buoyancy forces in damping the turbulence to be assessed. The vertical eddy diffusivity was calculated, following Osborn (1980), as

$$
\mathrm{K}_{\mathrm{Z}}=\frac{\mathrm{R}_{\mathrm{f}}}{1-\mathrm{R}_{\mathrm{f}}} \frac{\varepsilon}{\mathrm{N}^{2}}
$$

where $R_{f}$ is the flux Richardson number. This parameter was calculated using the method detailed by Ivey and Imberger (1991), who define it as the ratio of the buoyancy flux that occurs due to turbulent motions to the net mechanical energy required to sustain those motions, i.e. the efficiency of the turbulent motions in turning mechanical energy into potential energy. $\mathrm{K}_{\mathrm{Z}}$ provides the key measure of the rate at which turbulence transfers scalar quantities vertically.

Meteorological data covering a wide range of variables was provided for the period January 2002 to May 2004 by the Centre for Ecology and Hydrology, Lancaster, U.K. These data were taken from a meteorological buoy located less than $1 \mathrm{~km}$ from Priest Pot, on the adjacent, larger lake Esthwaite Water (surface area $\sim 1 \mathrm{~km}^{2}$; maximum depth $\sim 15 \mathrm{~m}$ ). Comparisons were made between hourly data from this buoy and those taken from a buoy deployed on Priest Pot during the previous year (which was not available during the summer 
of 2003). Data was missing from a significant part of 2002 for the Priest Pot buoy, due to instrument problems, but sufficient data was available to derive statistically significant relationships. The data show a strongly correlated linear relationship between air temperature values $\left(r^{2}=0.89 ; n=1689 ; \mathrm{p}<<0.001\right)$ from Esthwaite and Priest Pot. The amplitude of air temperature variations was on average $\sim 33 \%$ higher at Priest Pot than on Esthwaite $(\mathrm{t}=9.3$; df $=72 ; p<<0.001$ ), evidently due to the damping effect of the larger body of water at the

latter location. Wind speeds at these two locations are also well correlated $\left(\mathrm{r}^{2}=0.61 ; \mathrm{n}=\right.$ 4623; $\mathrm{p}<<0.001)$. The sheltered nature of Priest Pot is reflected in the wind speeds there, which are typically $\sim 75 \%$ of those measured at the Esthwaite buoy $(\mathrm{t}=3.8$; $\mathrm{df}=4622 ; \mathrm{p}<<$ 0.001). The final meteorological variable used in the analyses below, downwelling short wave solar radiation (measured $\sim 2 \mathrm{~m}$ above the water surface), has not been measured at Priest Pot, but its value is assumed to vary little over the $1 \mathrm{~km}$ spatial scale between the Esthwaite buoy where it was measured and Priest Pot. The period over which data was collected covered a wide range of meteorological forcing conditions. This resulted in a wide variety of different stratification and mixing regimes being sampled.

Figure 1

\section{Results}

Seasonal time scale variations in stratification

The seasonal variation of stratification in Priest Pot follows the classical pattern found in larger lakes. Figure 1a shows the variation of the overall stratification of the water column $\overline{\mathrm{N}}$ during 2002-2004. These data are calculated from temperature profiles recorded at approximately $0.25 \mathrm{~m}$ intervals during routine fortnightly monitoring of the pond, and SCAMP micro-scale temperature profiles taken during the dedicated field campaign in 2003. The pond starts to stratify in mid-March at Day of the Year (DY) 75, has a period of strong stratification between early June (DY 150) and the end of August (DY 240), reaches peak 
stratification in early August (DY 210-220) and has overturned by the end of September (DY 275). Peak $\overline{\mathrm{N}}$ values are typically around $0.07 \mathrm{~s}^{-1}$, with a maximum value of $0.09 \mathrm{~s}^{-1}$ recorded during the project reported here. During the summer, the stratification extends through most of the water column, although the bottom $\sim 0.5 \mathrm{~m}$ remains isothermal even when $\overline{\mathrm{N}}$ is maximal. In winter, there are occasional, weak stratifying events, either due to unseasonally warm weather, or to unusually cold periods (for this location) when the water surface temperature descends below $4^{\circ} \mathrm{C}$. Example profiles from throughout the year are shown in Figure $1 b$.

Figure 1c shows temperature variations over the whole period for which meteorological data was available, at $0.25 \mathrm{~m}$ depth intervals. A clear annual pattern is discernable, matching that classically found in monomictic lakes globally. From midwinter, there is a period when the whole water column warms but remains isothermal before the onset of stratification. The whole of the water column then continues to warm until the point of peak stratification, at a rate that increases with decreasing depth below the surface. After this peak, the stratification begins to break down from the surface downwards, thus there is a period where the surface water cools but the water at depth continues to warm, until the water column becomes warm and isothermal (usually in the latter half of September) whereafter it cools back to its midwinter state.

Figure 2

Several-day time scale variations in stratification.

Figure 1 indicates that there are clearly shorter time scale variations in overall stratification $\overline{\mathrm{N}}$ superimposed on the seasonal changes. These have been analysed by calculating correlations between $\overline{\mathrm{N}}$ and meteorological variables. Of these, air temperature provided the best correlation. In order to determine the time scale which characterises these sub-seasonal variations, correlation coefficients $r$ were calculated between $\overline{\mathrm{N}}$ values and the 
average air temperature $\overline{\mathrm{T}}_{\text {air }}(\mathrm{D})$ during the D days up to and including the day on which $\overline{\mathrm{N}}$ was measured $(\mathrm{D}=1$ to 15$)$. Both $\overline{\mathrm{N}}$ and $\overline{\mathrm{T}}_{\text {air }}(\mathrm{D})$ were seasonally de-trended for this calculation by subtracting the corresponding 90-day centrally-averaged mean. The correlation coefficient peaked at $\mathrm{D}=5$, for which $\mathrm{r}=0.82(\mathrm{n}=41 ; \mathrm{p}<<0.001$, Figure 2$)$. This implies that the time scale over which the whole water column in Priest Pot adjusts its overall stratification is of the order of five days, and thus that forcing mechanisms acting on this time scale are those which primarily determine the sub-seasonal variation of $\bar{N}$. This suggests that variations in general weather conditions due to the passage of atmospheric pressure systems, a process which typically occurs on a time scale of a few days, play a significant role in controlling the stratification of Priest Pot. This conjecture, however, requires further examination.

\section{Sub-daily time scale variation}

Although the shallowness of Priest Pot implies that nocturnal convective cooling might be expected to have a significant effect on its stratification, we focus here on the daytime structure of the water column, as this is when phytoplankton are photosyntheticallyactive and thus when turbulence-induced vertical cycling of them through the light attenuation curve will have a significant effect on their productivity. Visual inspection of the profiles obtained on the different days of the campaign show that there is a surface layer that may be distinguished from the rest of the water column by the way it is more strongly affected by variations in daytime meteorological parameter values, especially during the period of strong stratification during June-August. Taking - from observation of the SCAMP profiles $-0.5 \mathrm{~m}$ as a representative depth for this layer, its mean buoyancy frequency was calculated for profiles taken in this period and denoted $\overline{\mathrm{N}}_{0.5}$. Values of $\overline{\mathrm{N}}_{0.5}$ ranged from 0.02 to $0.12 \mathrm{~s}^{-1}$, giving values of $\overline{\mathrm{N}}_{0.5} / \overline{\mathrm{N}}$ from approximately 0.25 to 1.75 . These extremes represent well- 
mixed surface layer and strong near-surface stratification relative to the rest of the water column respectively. Correlations between $\overline{\mathrm{N}}_{0.5} / \overline{\mathrm{N}}$ and the available meteorological variables (see above) was calculated, of which the strongest was that with the intensity of downwelling short-wave radiation, integrated from 6 a.m. until midday on the day that the profiles were taken $(\mathrm{r}=0.59 ; \mathrm{n}=14 ; \mathrm{p}=0.01)$. As profiles were generally taken at around midday on each of the sampling days, this variable can be taken to represent the amount of daytime heating the lake received prior to the profiles being recorded. Calculating the water temperature increase due to the energy input from downwelling short wave radiation integrated over this time period each day, and assuming the this energy is shared through the top $0.5 \mathrm{~m}$ of water suggests realistic average temperature increases of 2 to $8^{\circ} \mathrm{C}$, thus backing up the inference of this statistical argument. Correlations with wind speed - both averaged over the SCAMP sampling period and integrated from 6 a.m. to midday on the sampling day were, by contrast, much weaker and not statistically significant. This provides evidence that the diurnal heating-cooling cycle is the dominant forcing factor on the stratification of this upper layer in Priest Pot and that wind-induced mixing has a relatively limited effect in this respect.

Figure 3

\section{Turbulence}

Values of the turbulent kinetic energy dissipation rate in the uppermost $0.5 \mathrm{~m}$ of the water column $\varepsilon_{0.5}$ were on the order $10^{-8} \mathrm{~m}^{2} \mathrm{~s}^{-3}$, which is small compared with those found in other measurements of surface layers (e.g., MacIntyre, 1993, who reported $10^{-7} \mathrm{~m}^{2} \mathrm{~s}^{-3}$ ). In a waterbody as small as Priest Pot with no inflows or outflows, it can be assumed that the source of turbulence is wind stress. Analysis of correlations with the available meteorological data showed that the strongest correlation $(\mathrm{r}=0.81 ; \mathrm{n}=14 ; \mathrm{p}<0.001)$ was with wind speed measurements, averaged between 11 a.m. and 2 p.m. on the SCAMP fieldwork days (i.e. the 
period during which the set of profiles was taken), corroborating this assumption. Further support for this theory is supplied by comparing estimates of the energy flux $F_{q}$ due to the wind stress at the water surface with the energy dissipation rate $\varepsilon$. Using the wind stress formulation of Large and Pond (1981) and wind speed data from Priest Pot in 2002, the order of magnitude of the shear velocity is calculated as $\mathrm{u}^{*} \sim 10^{-2} \mathrm{~ms}^{-1}$. Thus $\mathrm{F}_{\mathrm{q}}=1 / 2 \mathrm{C}_{\mathrm{N}}^{3} \mathrm{u}^{* 3}(\mathrm{Kim}$ 1976) where $C_{N}$ is of order unity (MacIntyre et al. 2002) gives the order of magnitude of the energy flux as $\mathrm{F}_{\mathrm{q}} \sim 10^{-6} \mathrm{~m}^{3} \mathrm{~s}^{-3}$. Given that Wüest et al. (2000) report that typically of the order of $1 \%$ of the wind energy flux is dissipated by turbulence in the mixed surface layer of lakes, this value of $\mathrm{F}_{\mathrm{q}}$ is consistent with the measured values of $\varepsilon \sim 10^{-8} \mathrm{~m}^{2} \mathrm{~s}^{-3}$, to the nearest order of magnitude.

Values of vertical turbulent eddy diffusivity $\mathrm{K}_{\mathrm{Z}}$ averaged on the order of $10^{-5} \mathrm{~m}^{2} \mathrm{~s}^{-1}$ with values in the range $10^{-4}-10^{-6} \mathrm{~m}^{2} \mathrm{~s}^{-1}$ in the upper layer, but were an order of magnitude smaller in the stratified water column below this. Again, these are small compared with measurements of the same variable using similar techniques found by, for example, MacIntyre (1993) in North Lake, Western Australia (surface area $2.9 \times 10^{5} \mathrm{~m}^{2}$; maximum depth 2.6m; $\mathrm{K}_{\mathrm{Z}} 10^{-3}$ to $10^{-5} \mathrm{~m}^{2} \mathrm{~s}^{-1}$ ) and Lorke (1998) in Müggelsee, Germany (surface area $7.3 \times 10^{6} \mathrm{~m}^{2}$; maximum depth $8 \mathrm{~m} ; \mathrm{K}_{\mathrm{Z}} 10^{-2}$ to $10^{-7} \mathrm{~m}^{2} \mathrm{~s}^{-1}$ ).

Analysis of the nature of the turbulence found in the SCAMP profiles using plots of the turbulent Froude and Reynolds numbers $-\operatorname{Fr}_{\mathrm{T}}$ and $\mathrm{Re}_{\mathrm{T}}$ respectively - known as hydrodynamic phase diagrams (Ivey and Imberger, 1991) illustrate that, during the period of strong stratification from June to August, "active" turbulence (i.e. overturns untrammelled by damping due to viscosity or buoyancy) is found in the upper layer when it is well-mixed, but does not penetrate below this into the stratified layer, as shown for July $28^{\text {th }}$ in Figure 3 a. Neither does active turbulence occur in the upper layer when it too is stratified, as shown for August $8^{\text {th }}$ in Figure 3b. In these stratified layers, the turbulence is predominantly damped by 
both viscosity and buoyancy, as shown. As the stratification starts to break down at the end of August, active turbulence is able to penetrate below the top $0.5 \mathrm{~m}$ of the water column (Figure 4a) and is common throughout the water column once the pond has overturned at the start of October (Figure 4b).

Figure 4 On July $28^{\text {th }}$, when the depth of the surface mixed layer was $\sim 0.4 \mathrm{~m}$, the maximum Thorpe displacement $\mathrm{L}_{\operatorname{Tmax}}$ was $\sim 0.1 \mathrm{~m}$. In the strongly stratified regime found on August $8^{\text {th }}$, $\mathrm{L}_{\text {Tmax }}$ was of the order of a few centimetres, an order of magnitude smaller than the length scale of the layers of fluid with slightly less than the profile-average temperature gradient which are discernable in the profile. These two days are representative of the mixed and stratified cases observed on the other data collection days respectively. Thus, in both these cases, the wind-induced turbulence was too weak to produce overturns with length scales comparable to the mixed layer depth. This provides evidence that vertical transport in this region during the daytime is mediated by the quasi-diffusive effect of many small overturns, rather than the advective effect of single large overturns.

\section{Discussion}

The significance of this work lies in its elucidation of the character of the stratification and turbulent mixing within Priest Pot, which stands as a particularly species-rich example of the type of ponds which make a major contribution to species diversity (e.g. Oertli et al., 2005). The understanding of the physical framework provided, and the evidence presented to support the picture presented, provide important underpinning for the development of approaches to enhancing and sustaining the ecological health of these environments.

Priest Pot shows many of the characteristics classically found in lakes during the summer: a permanently stratified water column with a distinct surface layer which mixes and re-stratifies on a diurnal basis, a strongly stratified metalimnetic layer within which the 
oxycline occurs and a relatively isothermal benthic layer. What is surprising about Priest Pot is that all this structure occurs in a small pond with a surface area of only a hectare and a maximum depth of only $3.5 \mathrm{~m}$. Usually, waterbodies this shallow tend to be much more sensitive to meteorological forcing (e.g., Talling, 2001) and have a stronger mixing regime (e.g., MacIntyre, 1993). Spence et al. (2003) measured Skeeter Lake (surface area $5 \times 10^{4} \mathrm{~m}^{2}$; maximum depth 6.6m) in Northern Canada, and arguably the conditions closest to those in Priest Pot that have been reported in the literature. They focus their work on the surface heat flux budget, noting that the relative lack of penetration of heat from the atmosphere caused by a relatively weak mixing regime and strong near-surface attenuation of radiation means that more heat is available in the near surface waters for evaporative exchange into the atmosphere. Thus the strongly stratified summer character of small waterbodies such as Priest Pot and Skeeter Lake is important for their climatic influence. Although individually, this influence will be very small for waterbodies of this size, their abundance (as noted above) implies that their concerted effect will be significant.

Three factors can be identified whose potential as causes of Priest Pot's unusually unmixed character are supported by the observations reported here. Firstly, Priest Pot is relatively sheltered causing wind speeds to be, on average, $75 \%$ of those measured less than a kilometre away on Esthwaite Water. Together with the lack of fetch available to the wind Priest Pot's longest axis measures less than $200 \mathrm{~m}$ - this suggests that wind-induced mixing will be limited. Secondly, the presence of high concentrations of seston in the water column, which were clearly evident during fieldwork, can be reasonably expected to limit the penetration of radiation below the surface layer and exacerbate the stratification.

Figure 5 Finally, Priest Pot experiences rather modest (in a global context) diurnal variations in ambient air temperature, as would be expected of the temperate, maritime climate in which it is situated. This is illustrated by the data presented in Figure 5, which shows that the diurnal 
temperature range for Priest Pot during the summer has an average value of $6.1^{\circ} \mathrm{C}$. This is significantly less than typical global values for diurnal temperature range (see, for example, Figure 3 of Essery et al. (2003), which displays summer values of $\geq 10^{\circ} \mathrm{C}$ for a wide range of climatic regions). This is likely to limit the effect of nocturnal convective cooling, as evidenced by the location of the oxycline at $\sim 1 \mathrm{~m}$ depth throughout the summer (data not presented). We can test this assumption by calculating the order of magnitude of the turbulent dissipation rate due to convective cooling, which may be taken to be equivalent to the order of magnitude of the convective buoyancy flux. To calculate this, we determine the surface heat flux $\mathrm{H}$, which is given by

$$
\mathrm{H}=\mathrm{Q}_{\mathrm{lo}}^{\text {in }}-\mathrm{Q}_{\mathrm{lo}}^{\text {out }}+\mathrm{Q}_{\mathrm{h}}+\mathrm{Q}_{\mathrm{e}}
$$

where $\mathrm{Q}_{\mathrm{lo}}^{\text {in }}=\varepsilon_{\mathrm{A}} \sigma \mathrm{T}_{\mathrm{A}}^{4}$ and $\mathrm{Q}_{\mathrm{lo}}^{\text {out }}=\varepsilon_{\mathrm{W}} \sigma \mathrm{T}_{\mathrm{W}}^{4}$ are the long wave radiative influx and efflux respectively ( $\varepsilon$ is emissivity, $\sigma=5.67 \times 10^{-8} \mathrm{Wm}^{-2} \mathrm{~K}^{-4}, \mathrm{~T}$ is the temperature in Kelvin and the subscripts A and W denote values for air and water respectively), $\mathrm{Q}_{\mathrm{h}}=\rho_{\mathrm{A}} \mathrm{C}_{\mathrm{pA}} \mathrm{C}_{\mathrm{h}} \mathrm{U}_{\mathrm{A}}\left(\mathrm{T}_{\mathrm{W}}-\mathrm{T}_{\mathrm{A}}\right)$ is the sensible heat flux $\left(\rho_{\mathrm{A}}=1.2 \mathrm{kgm}^{-3}\right.$ is air density, $\mathrm{C}_{\mathrm{pA}}$ $=1000 \mathrm{Jkg}^{-1} \mathrm{~K}^{-1}$ is the specific heat capacity of air, $\mathrm{C}_{\mathrm{h}}=1.4 \times 10^{-3}$ is a transfer coefficient (Hicks, 1972; Jones et al. 2005) and $\mathrm{U}_{\mathrm{A}}$ is the wind speed) and $\mathrm{Q}_{\mathrm{e}}=\rho_{\mathrm{A}} \mathrm{LC}_{\mathrm{e}} \mathrm{U}_{\mathrm{A}}\left(\mathrm{q}_{\mathrm{W}}^{*}-\mathrm{q}_{\mathrm{A}}\right)$ is the latent heat flux $\left(\mathrm{L}=2.45 \times 10^{6} \mathrm{Jkg}^{-1}\right.$ is the specific latent heat of evaporation, $\mathrm{C}_{\mathrm{e}}=1.4 \times 10^{-3}$ is a transfer coefficient (Hicks, 1972; Jones et al. 2005), $\mathrm{q}_{\mathrm{W}}^{*}$ is the saturated specific humidity at the water surface and $\mathrm{q}_{\mathrm{A}}$ is the specific humidity of the air. Water surface temperature and wind speed values for these calculations were taken from the summer 2002 records for Priest Pot. The air temperature values were not available at Priest Pot for this period, but were calculated from air temperature data from the nearby Esthwaite Water meteorological buoy 
(see above) using a linear regression between data at these two sites at times when both were available. Relative humidity and atmospheric pressure measurements were also taken from the Esthwaite Water buoy, as they were not available at Priest Pot. Neither of these last two variables was expected to vary significantly over the $1 \mathrm{~km}$ distance between the Esthwaite Water buoy and Priest Pot, so their values were not adjusted in any way. The buoyancy flux $B$ is defined as

$$
\mathrm{B}=\frac{\mathrm{g} \alpha \mathrm{H}}{\mathrm{C}_{\mathrm{pW}} \rho_{0}}
$$

where $\mathrm{g}$ is gravitational acceleration, $\alpha$ the thermal expansion coefficient of water (calculated as $\alpha=1.6 \times 10^{-5}+9.6 \times 10^{-6} \mathrm{~T}_{\mathrm{W}}$ where $\mathrm{T}_{\mathrm{W}}$ is in degrees Celsius) and $\rho_{0}$ is a reference water density value. This gave average values of $\mathrm{B} \sim 10^{-8} \mathrm{~m}^{2} \mathrm{~s}^{-3}$, which is the same order of magnitude as the dissipation values for the weak, wind-driven turbulence measured during the day. To calculate an order of magnitude measure of the penetrative depth $\mathrm{L}_{\mathrm{P}}$ for convection characterised by this buoyancy flux, we note that $\mathrm{L}_{\mathrm{P}}=\mathrm{L}_{\mathrm{P}}(\mathrm{B}, \mathrm{N})$, and thus by dimensional arguments $L_{P} \sim\left(B / N^{3}\right)^{1 / 2}$. For a range of values of $N=10^{-2}-10^{-1} \mathrm{~s}^{-1}$ (c.f. Figure 1a) that might be expected below the surface mixed layer, this gives $L_{P} \sim 10^{-5 / 2}-10^{-1} \mathrm{~m}$, i.e. on the order of a few centimetres to ten centimetres. This is consistent with the inference that the oxycline depth is an indication of the maximum extent of nocturnal convective cooling. The implication of this is that the variation in the stratification of the surface layer is governed dominantly by variations in the fluxes of radiative, sensible and latent heat at the water surface, rather than by either wind-induced mixing, and that the convective mixing due to nocturnal surface heat losses is limited to the upper few tens of centimetres of the water column. However, this conclusion remains somewhat speculative, because we have no direct 
measurements of the nocturnal convective cooling. Further work is thus required to clarify this issue.

The data presented here provides evidence that the key meteorological forcing factors have more clearly separate roles here than in more open waterbodies. The strong (weak) correlation between surface layer stratification and solar radiation (wind speed) described above and the character of the surface layer turbulence (Figure 3) suggest that the thermal structure of the water column is due pre-dominantly to heating and cooling, rather than wind forcing, and that the wind causes active turbulence only in mixed layers already set up by the thermodynamic processes. The turbulence it produces is characterised by length scales which are much smaller than the depth of the mixed layer, implying diffusion-like vertical transport. As a result, and taking the r.m.s. Thorpe scale $\mathrm{L}_{\mathrm{T}}$ to represent the typical overturn length scale, the time it takes for a patch of plankton to spread over the extent of a turbulent overturn is $\mathrm{L}_{\mathrm{T}}{ }^{2} / 8 \mathrm{~K}_{\mathrm{Z}}$ (MacIntyre, 1993), which for the surface mixed layers observed here has a value on the order of five seconds. This is so small because the overturns are only one or two centimetres wide, and is much smaller than the time scale $\pi / \overline{\mathrm{N}}_{0.5}$ over which the overturns are providing a positive buoyancy flux, prior to restratifying at later times (MacIntyre, 1993), which here is on the order of a minute. This implies that the efficiency with which the phytoplankton in the surface mixed layer are mixed through the light attenuation curve is not hampered by the stratification $\left(\overline{\mathrm{N}}_{0.5}\right)$ of the water column.

The picture of the physical structure of Priest Pot's water column that has emerged in this paper may have been at least partially assumed a priori, but the work reported has contributed both a clarification of the role of the meteorological, climatic and environmental context of the pond, and evidence to support this picture. The strength and persistence of the stratification provides a multiplicity of ecological niches, enabling the pond to accommodate a wide variety of organisms in a small space and giving it its unusually high biodiversity (see 
Finlay and Maberley, 2000). The weakness and lack of penetration of vertical mixing at the centre of the pond implies that some other mechanism must be dominantly responsible for supplying nutrients to the surface layer. Although these views are purely speculative, intuition suggests that the lack of fetch is likely to constrain strongly the formation of internal seiches and other internal wave motions. Thus we theorise that nutrient resuspension near the pond edge due to internal wave breaking is likely to be weak. A more likely candidate may be supply of nutrients by groundwater flow into the pond. Priest Pot sits in a moist context, being is surrounded by marsh and carr, and is known to have a significant groundwater input (S. Maberley, pers. comm.). The groundwater input is not so strong that it showed up clearly in any of the SCAMP profiles, but it may provide an input of nutrient-rich water at the pond's shore that could then be transported to its centre via, for example, gravity currents formed by differential heating. As noted, however, these ideas are purely speculative, and current research (Coates and Folkard, in preparation) is aimed at understanding the effects of near shore processes on the physical structure of this valuable waterbody.

\section{Acknowledgements}

Funding for this work was provided by the UK Natural Environment Research Council through the award of grant NER/B/S/2002/00532. Access to Priest Pot and its boating facilities was provided by the Freshwater Biological Association. Meteorological and water temperature data from fortnightly routine monitoring work were provided by the Centre for Ecology and Hydrology Windermere/Lancaster Laboratory. Stephen Maberley provided vital background information and a personal introduction to the facilities at Priest Pot. Mike and Sandy Head, and Jonathan Sharples provided advice regarding the use of SCAMP. Andy Quin assisted with fieldwork. Two anonymous referees made comments which led to significant improvements in the paper. To all these, the authors extend their sincere gratitude. 


\section{References}

Biggs J, Williams P, Whitfield M, Nicolet P, Weatherby A (2005) 15 years of pond assessment in Britain: results and lessons learned from the work of Pond Conservation. Aquat Conserv 15:693-714

Dillon TM, Caldwell DR (1980) The Batchelor spectrum and dissipation in the upper ocean. J Geophys Res-Oceans 85:1910-1916

Essery RLH, Best MJ, Betts RA, Cox PM (2003) Explicit Representation of Subgrid Heterogeneity in a GCM Land Surface Scheme. J Hydrometeorol 4:530-543

Finlay BJ, Maberley SC (2000) Microbial diversity in Priest Pot, a productive pond in the English Lake District. Freshwater Biological Association, Ambleside

Hicks BB (1972) Some evaluations of drag and bulk transfer coefficients over water bodies of different sizes. Bound-Lay Meteorol 3:201-213

Ivey GN, Imberger J (1991) On the nature of turbulence in a stratified fluid. 1. The energetics of mixing. J Phys Oceanogr 21:650-658

Jacobs AFG, Heusinkveld BG, Nieveen JP (1998) Temperature behavior of a natural shallow water body during a summer period. Theor Appl Climatol 59:121-127 
Jacobs AFG, Jetten TH, Lucassen DC, Heusinkveld BG, Nieveen JP (1997) Diurnal temperature fluctuations in a natural shallow water body. Agr Forest Meteorol 88:269-277

Jones I, George DG, Reynolds CS (2005) Quantifying effects of phytoplankton on the heat budgets of two large limnetic enclosures. Freshwater Biol 50:1239-1247

Kim JW (1976) A generalized bulk model of the oceanic mixed layer. J Phys Oceanogr 6:686-695

Large WG, Pond S (1981) Open ocean momentum flux measurements in moderate to strong winds. J Phys Oceanogr 11:324-336

Lorke A (1998) Investigation of turbulent mixing in shallow lakes using temperature microstructure measurements. Aquat Sci 60:210-219

MacIntyre S (1993) Vertical mixing in a shallow, eutrophic lake: possible consequences for the light climate of phytoplankton. Limnol Oceanogr 38:798-817

MacIntyre S, Romero JR, Kling GW (2002) Spatial-temporal variability in surface layer deepening and lateral advection in an embayment of Lake Victoria, East Africa. Limnol Oceanogr 47:656-671

Oertli B, Biggs J, Cérérghino R, Grillasd P, Jolye P, Lachavanne J-B (2005) Conservation and monitoring of pond biodiversity: introduction. Aquat Conserv 15:535-540 
Osborn, TR (1980) Estimates of the local-rate of vertical diffusion from dissipation measurements, J Phys Oceanogr 10: 83-89

Spence C, Rouse WR, Worth D, Oswald C (2003) Energy budget processes of a small northern lake. J Hydrometeorol 4:694-701

Talling JF (2001) Environmental controls on the functioning of shallow tropical lakes. Hydrobiologia 458:1-8

Thorpe SA (1977) Turbulence and mixing in a Scottish loch. Philos T Roy Soc A 286: 125181

Williams P, Whitfield M, Biggs J, Bray S, Fox G, Nicolet P, Sear D (2004) Comparative biodiversity of rivers, streams, ditches and ponds in an agricultural landscape in Southern England. Biol Conserv 115:329-341

Williams P, Biggs J, Barr C, Cummins C, Gillespie M, Rich T, Baker A, Baker J, Beesley J, Corfield A, Dobson D, Culling A, Fox G, Howard D, Luursema K, Rich M, Samson D, Scott W, White R, Whitfield M (1998) Lowland Pond Survey 1996. Department of the Environment, Transport and the Regions, London

Wüest AJ, Piepke G, Van Senden DC (2000) Turbulent kinetic energy balance as a tool for estimating vertical diffusivity in wind-forced stratified waters. Limnol Oceanogr 45:13881400 
Xenopoulos MA, Schindler DW (2001) The environmental control of near-surface thermoclines in boreal lakes. Ecosystems 4:699-707 


\section{Figure Captions}

Figure 1: Seasonal stratification patterns in Priest Pot: A) variation of the overall stratification of the water column $\overline{\mathrm{N}}$ during 2002-2004. Data are calculated from temperature measurements recorded at approximately $0.25 \mathrm{~m}$ intervals (clear diamonds) and SCAMP micro-scale temperature profiles recorded during July-October 2003 (black squares) - solid line indicates 5-point rolling mean; B) example temperature profiles; and C) temperature variations from January 2002 to May 2004 at $0.25 \mathrm{~m}$ depth intervals. Seasons in (B) are defined as 3 month periods starting on the first days of March, June, September \& December.

Figure 2: Relationship between seasonally de-trended $\overline{\mathrm{N}}$ (full-depth mean buoyancy frequency) and $\overline{\mathrm{T}}_{\text {air }}(5)$ (mean air temperature over five days preceding $\overline{\mathrm{N}}$ measurements) values, for which $\mathrm{r}^{2}=0.82$ (see text for details).

Figure 3: A) Plots of $\mathrm{K}_{\mathrm{Z}}$ values, distinguished according to the hydrodynamic phase diagram sector they fall into, measured in individual SCAMP casts recorded on July $28^{\text {th }} 2003$, with temperature profile included to show location of mixed and stratified layers; B) as for (A) for August $8^{\text {th }}$ 2003. C) Hydrodynamic phase diagram (sensu Ivey and Imberger 1991) for July

$28^{\text {th }}$ distinguishing turbulence in the surface mixed layer from that in the stratified layer below it: the four sectors of the plot correspond to the four states of turbulence in A and B, as denoted; D) as for (C) for August $8^{\text {th }}$, when the whole water column was strongly stratified.

Figure 4: As for Figure 3 for A) August 26 ${ }^{\text {th }} 2003$; A) October $7^{\text {th }} 2003$. 
Figure 5: Frequency distribution of diurnal temperature amplitude at Priest Pot for mid-March to mid-October 2003. Temperature data derived by converting data from Esthwaite Water meteorological buoy using regression obtained from 2002 data. 

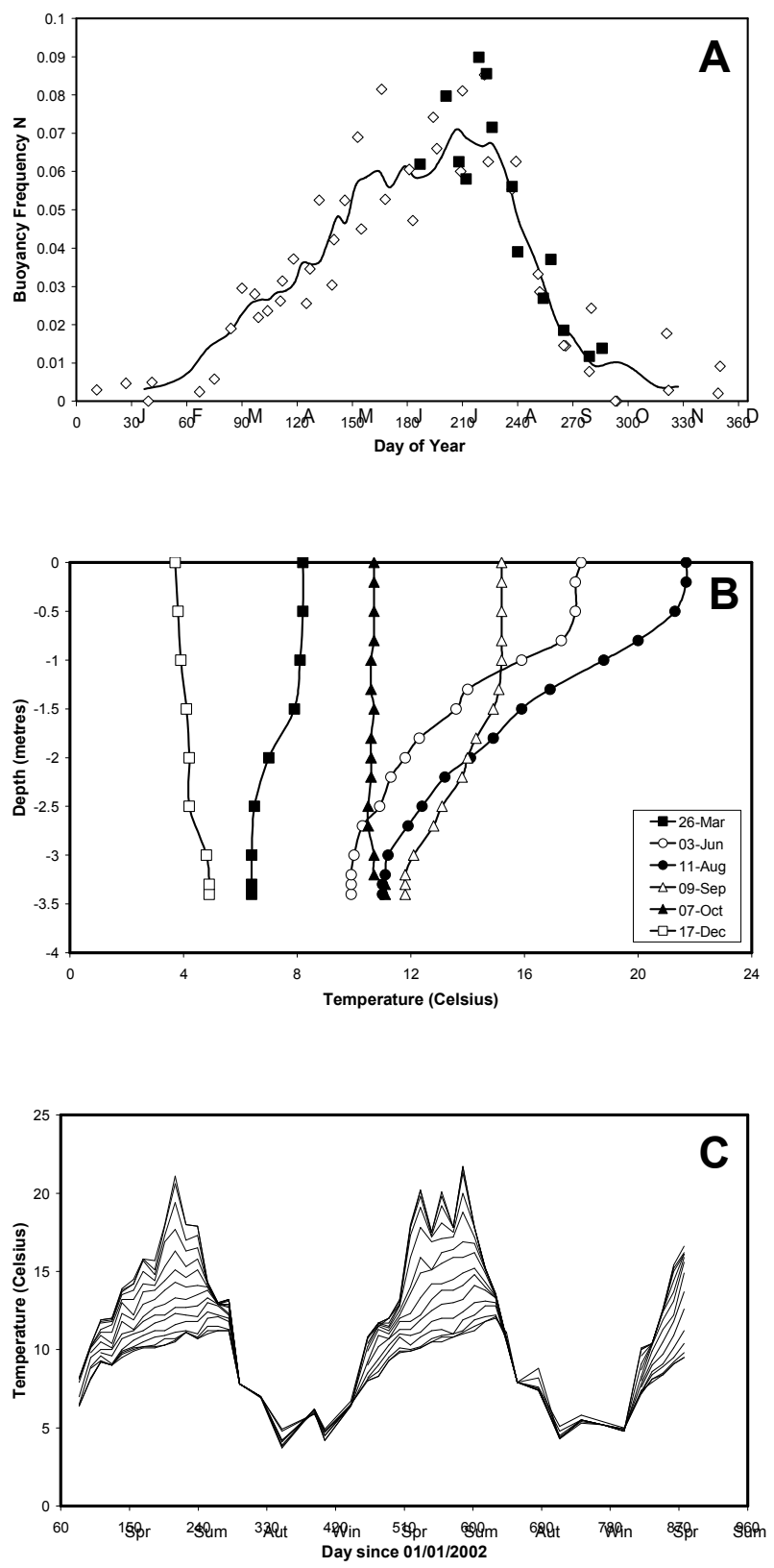

Folkard et al., Figure 1 


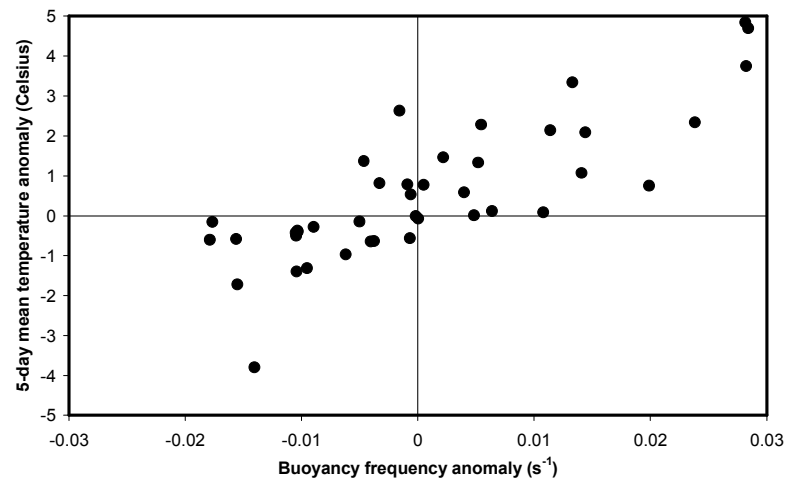

Folkard et al., Figure 2 

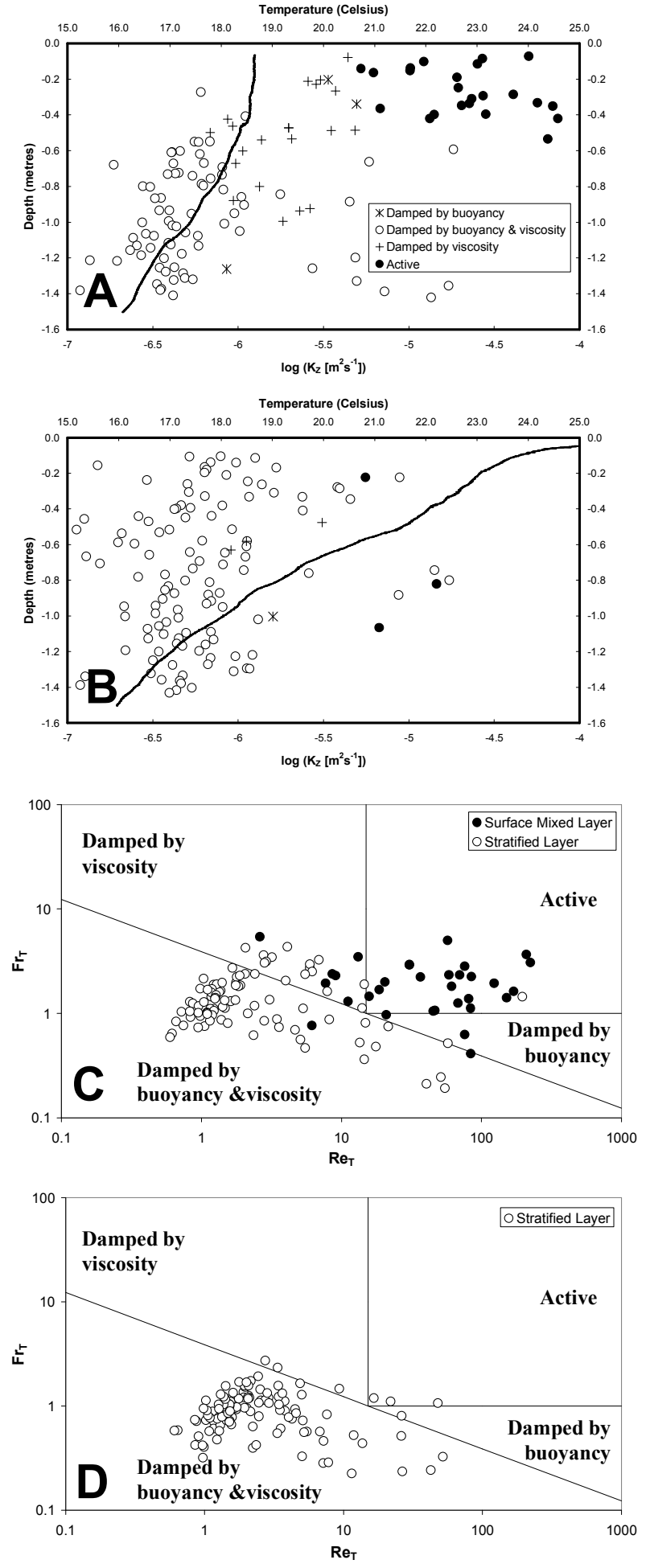

Folkard et al., Figure 3 

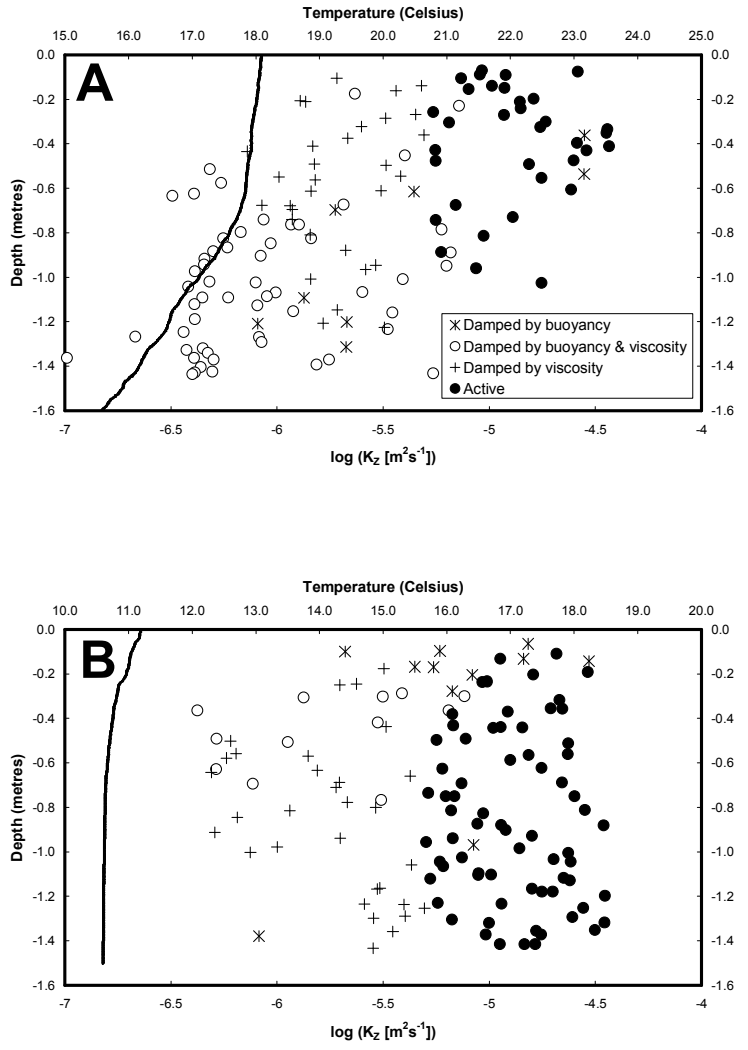

Folkard et al., Figure 4 


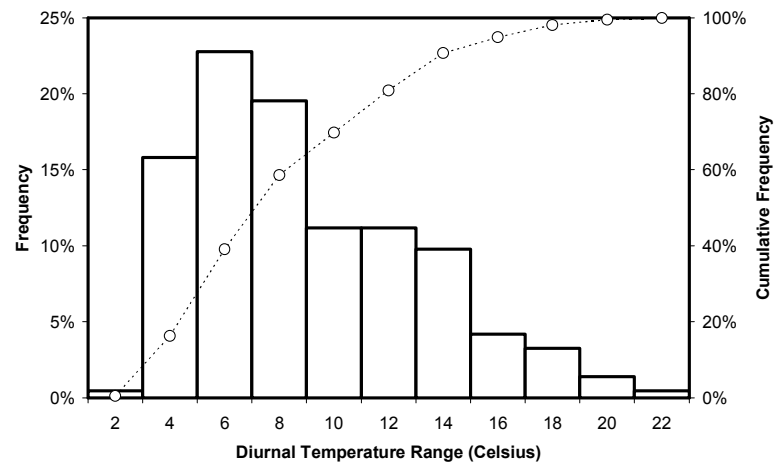

Folkard et al., Figure 5 